\title{
Vitronectin as a molecular player of the tumor microenvironment in neuroblastoma
}

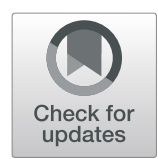

Rebeca Burgos-Panadero ${ }^{1,2}$, Inmaculada Noguera ${ }^{3}$, Adela Cañete ${ }^{4}$, Samuel Navarro ${ }^{1,2}$ and Rosa Noguera ${ }^{1,2^{*}}$ (D)

\begin{abstract}
Background: Vitronectin is a multifunctional glycoprotein known in several human tumors for its adhesive role in processes such as cell growth, angiogenesis and metastasis. In this study, we examined vitronectin expression in neuroblastoma to investigate whether this molecule takes part in cell-cell or cell-extracellular matrix interactions that may confer mechanical properties to promote tumor aggressiveness.

Methods: We used immunohistochemistry and image analysis tools to characterize vitronectin expression and to test its prognostic value in 91 neuroblastoma patients. To better understand the effect of vitronectin, we studied its in vitro expression using commercial neuroblastoma cell lines and in vivo using intra-adrenal gland xenograft models by immunohistochemistry.

Results: Digital image analysis allowed us to associate vitronectin staining intensity and location discriminating between territorial vitronectin and interterritorial vitronectin expression patterns. High territorial vitronectin expression (strong staining associated with pericellular and intracellular location) was present in tumors from patients with metastatic undifferentiating neuroblastoma, that were MYCN amplified, 11q deleted or with segmental chromosomal profiles, in the high-risk stratification group and with high genetic instability. In vitro studies confirmed that vitronectin is expressed in tumor cells as small cytoplasmic dot drops. In vivo experiments revealed tumor cells with high and dense cytoplasmic vitronectin expression.
\end{abstract}

Conclusions: These findings highlight the relevance of vitronectin in neuroblastoma tumor biology and suggest its potential as a future therapeutic target in neuroblastoma.

Keywords: Extracellular matrix, Vitronectin, Digital pathology, Migration, Neuroblastoma

\section{Background}

The composition, morphology and organization of the extracellular matrix (ECM) is key to both healthy and pathological environments. In healthy tissue, the ECM regulates development and homeostasis, whereas in tumors it displays mechanical properties such as stiffness that confer malignant characteristics to cell behaviour including proliferation, cell-death resistance, angiogenesis, invasion and metastasis [1-3]. The interaction between tumor cells and their surrounding elements is the first step in the development of metastasis, since cell movement requires firm cell-ECM adhesions to break down, as well as molecules to guide the migration.

\footnotetext{
* Correspondence: rnoguera@uv.es

${ }^{1}$ Pathology Department, Medical School, University of Valencia-INCLIVA, Valencia, Spain

${ }^{2}$ CIBERONC, Madrid, Spain

Full list of author information is available at the end of the article
}

Different cancer-promoting biological pathways of interest for further exploration are cell-cell or cell-ECM adhesions, proteases and chemokines [4]. In addition, recent studies show that cancer invasion and metastasis are driven by physical and chemical interactions between tumor cells and the ECM that translate into a stiff neoplastic ECM and soft or deregulated tumor cells, which in turn lead to a more favorable microenvironment for cancer dissemination [5-8].

Vitronectin (VN) is an adhesive glycoprotein that acts as a link between cells and the ECM through several ligands such as: integrins, plasminogen activator inhibitor-1(PAI-1) and urokinase plasminogen activator receptor (uPAR). VN is present in plasma as a monomeric or dimeric structure (folded or native form) and in the ECM of several tissues as a multimeric formation (unfolded or active form) [9, 10]. It is mainly synthesized

(c) The Author(s). 2019 Open Access This article is distributed under the terms of the Creative Commons Attribution 4.0 International License (http://creativecommons.org/licenses/by/4.0/), which permits unrestricted use, distribution, and 
by hepatocytes in the liver, although it has also been found in smaller amounts in extrahepatic tissues such as: brain, lung, kidney and vascular wall of adrenal gland [11-13]. It has also been observed that some tumor cells secrete $\mathrm{VN}$ as well as tumor-infiltrating T-lymphocytes (TIL) which bind to VN through TIL uPAR expression $[14,15]$. The biological functions of $\mathrm{VN}$, derived from its domains which bind several ligands in its activated form, are: preservation of vascular homeostasis (thrombosis and fibrinolysis), control of the innate immune system, facilitating cell adhesion and participation in migration in tissue repair and regeneration [16]. $\mathrm{VN}$ has a role in the provisional matrix of tumors, where it can promote cell adhesion and matrix degradation by binding to integrins, PAI-1 and uPAR [17]. In fact, in several human neoplasms, $\mathrm{VN}$ is associated with tumor invasion, metastasis and angiogenesis [18-20].

Neuroblastoma (NB) originates from the neural crest in the Sympathetic Nervous System and is one of the most common pediatric solid tumors [21]. Although several clinical, biological and genetic markers define the risk of progression in NB patients [22], the mechanisms that control communication between tumor cells and the ECM, and can influence aggressiveness are not yet clear. Our group has already described the aggressive pattern of a stiff ECM defined as: ECM with cross-linked and disorganized reticulin fiber networks, scant amount of collagen type I fibers and glycosaminoglycans and large and abundant irregularly-shaped and high blood vessels, associated with a poor outcome in NB patients [23-26]. Hence, to better comprehend this tumor cell-ECM communication we searched for targets within the ECM elements. Previous studies in NB have noted $\mathrm{VN}$ expression in ganglion cells that could suggest a differentiation role for this molecule [12] and its $\alpha_{\mathrm{v}} \beta_{3}$ integrin receptor, which is highly expressed in high-risk NB [27].

In this study, we used digital image analysis to examine the immunohistochemical expression of $\mathrm{VN}$ in $\mathrm{NB}$ to better understand the mechanical signals between neuroblasts and the ECM and their influence on tumor growth, differentiation and dissemination. In addition, we have done in vitro and in vivo experiments to assess if $\mathrm{VN}$ present in tumor or host microenvironments shows any modification on NB behavior since previous research showed the relationship between $\mathrm{VN}$ and metastasis and tumor progression in several human neoplasms.

\section{Methods}

\section{Patient samples}

A total of 91 primary NB tumors (at least two representative cylinders of $1 \mathrm{~mm}$ ) included in tissue microarrays (TMAs) were chosen according to NB genetic instability criteria [28], and classified into the following categories: very low instability (numerical chromosomal aberration (NCAs) profiles, defined as gains or losses of a whole chromosome), low instability ( $\leq 3$ typical segmental chromosomal aberrations (SCAs), excluding 11q deleted (11qD) profiles, defined as gains or losses of chromosomal fragments), medium instability (profiles with MYCN amplified (MNA) or $11 \mathrm{qD}$, both genetic markers of worse prognosis or $>3$ typical SCAs) and high instability (profiles with chromothripsis, defined as a local breaking with subsequent aleatory reassembly of fragment in a single event [28], or $>3$ gene amplifications), these categories were dichotomized as low instability (very low and low groups) versus high instability (medium and high groups). All samples had been referred to the Spanish Reference Centre for NB Biological and Pathological studies (Department of Pathology, University of Valencia-INCLIVA) from 2000 to 2015. The samples were also classified according to INRG clinicobiological parameters [22] (Additional file 1: Table S1). This study was approved by the Ethical Committee of the University of Valencia (reference B.0000339 29/01/ 2015). Participants or their family members/legal guardians provided written informed consent for histological and genetic studies performed in our laboratory. Clinical data were provided by the pediatric oncologists in charge or by the Reference center for NB clinical studies.

\section{Immunohistochemistry}

One $3 \mu \mathrm{m}$ section of each TMA was cut and immunostained with rabbit monoclonal antibody against VN (EP873Y, Clone; ab45139, Abcam, Cambridge, MA, USA) at 1:100 using OptiView Amplification Kit (Ventana Medical Systems Inc., Tucson, EE.UU.) in the BenchMark XT automated slide staining system (Ventana Medical Systems Inc., Tucson, USA). To determine the optimal antibody dilution, normal liver tissue and whole NB sections were used. As controls we stained several normal tissues (liver, kidney, salivary gland, smooth muscle, striated muscle, trachea, pancreas, spleen, adrenal gland, colon and placenta). Immunoreactivity was assessed by two researchers. VN immunoreaction was rated as no staining (0), and weak (1+), moderate $(2+)$, and strong (3+). This category was dichotomized as weak to moderate vs strong. This was used to determine the adequacy of a further image analysis and help setting the image analysis parameters.

\section{Image analysis}

All immunostained slides were digitized with the whole-slide Pannoramic MIDI scanner (3DHISTECH Ltd., Budapest, Hungary) at 20x magnification. We used two applications to quantify $\mathrm{VN}$ in $\mathrm{NB}$ samples: Image Pro-Plus (IPP) software v.6.0 (Media Cybernetics Inc., 
Silver Spring, MD, USA) and DensitoQuant module (DensitoQ), Pannoramic viewer software 1.15 (3DHISTECH Ltd., Budapest, Hungary). The second was used as a validation tool of the first as it allows quick segmentation based on immunohistochemical staining intensity. The steps used for IPP and DensitoQ macro customization are described in Additional file 2: Table S2. Examples of how these two applications work are provided in Additional file 3: Figure S1.

IPP: To characterize VN expression, a macro was customized using control tissues through RGB color segmentation; restrictive values were used to distinguish between VN staining intensity and location. We quantified VN staining as weak to moderate or strong, and VN distribution was identified as intercellular only or pericellular plus intracellular location. In addition, the percentage of $\mathrm{VN}$ stained area (\%SA) per cylinder and the mean of the two cylinders belonging to the same case were calculated as the area positive for $\mathrm{VN}$ divided by the total area of the cylinder, multiplied by 100 . The $\%$ SA and density (number of objects $/ \mathrm{mm}^{2}$ ) of cell nuclei of each case were also quantified.

DensitoQ: The measures obtained were: negative, weak, moderate and strong pixels intensity and $\mathrm{H}$-score. The H-score (or "histo" score), is a score that indicates if the sample can be considered positive or negative on the basis of a specific discriminatory threshold, ranging from 0 to 300 [29].

\section{Statistical methods}

All data were analyzed using SPSS statistical analysis software (version 24). The consistency between the subjective assessment and the $\mathrm{VN}$ image analysis was analyzed using the non-parametric Kruskal-Wallis test. Samples with no immunoreactivity for VN were excluded from the statistical analysis. The VN numerical continuous variables derived from the morphometric analysis that did not follow a normal distribution were related to the INRG prognostic categories using the non-parametric Mann-Whitney and Kruskal-Wallis tests and were dichotomized using the third quartile $\left(Q_{3}\right)$ to perform a survival analysis using the Kaplan-Meier curves and log-rank test. Cox survival regression using Wald (step back) test was used to estimate the influence of VN linked to INRG prognostic factors as independent variables on event-free and overall survival (EFS and OS, respectively). We considered $p$-values less than 0.05 as statistically significant.

\section{In vitro and in vivo models}

In vitro and in vivo models were used to evaluate the changes in neuroblasts VN expression independently of the hepatic/extrahepatic VN synthesis.
SH-SY5Y and SK-N-BE (2) NB cell lines were a generous gift from Miguel F. Segura (Laboratory of Translational Research in Child and Adolescent Cancer, Hospital Universitari Vall d'Hebron) and were grown, since $\mathrm{VN}$ is a fetal bovine serum component, in complete and serum-free media as indicate in Additional file 4: Table S3. To detect VN expression, cells were detached by Trypsin/EDTA $0.25 \%$ (Gibco; Thermo Fisher Scientific Inc.), deposited onto poly L-lysine coated (Sigma) slides using Shandon CytoSpin III Cytocentrifuge at $1200 \mathrm{rpm}$ for $10 \mathrm{~min}$, fixed with methanol/acetone $(1: 1)$ for $10 \mathrm{~min}$ at room temperature and stained as indicated previously.

Mice deficient in $\mathrm{VN}^{-/-}\left(\mathrm{B} 6.129 \mathrm{~S} 2\right.$ (D2)- $\left.\mathrm{Vtn}^{\mathrm{tm} 1 \mathrm{Dgi}} / \mathrm{J}\right)$ and $\mathrm{RAG}^{-/-}\left(\mathrm{B} 6.129 \mathrm{~S} 7-\mathrm{Rag} 1^{\mathrm{tm} 1 \mathrm{Mom}} / \mathrm{J}\right)$ were obtained from Jackson Laboratory (USA) and Charles River Laboratories (France) and interbred to homozygosis for both alleles. Four-to six-week-old female or male $\mathrm{RAG}^{-/-} \mathrm{VN}^{+/+}$(control) and $\mathrm{RAG}^{-/-} \mathrm{VN}^{-/-}$(experimental) mice were used for left adrenal injection of $1 \times$ $10^{6} \mathrm{SH}-\mathrm{SY} 5 \mathrm{Y}(n=20)$ and SK-N-BE $(2)(n=20) \mathrm{NB}$ cells lines in $30 \mu \mathrm{l}$ of $(1: 1)$ Dulbecco's phosphate-buffered saline (DPBS; Gibco; Thermo Fisher Scientific Inc.) and Matrigel (Corning; Cultek S.L.U, Barcelona, Spain). Mice were anaesthetised using $4-5 \%$ isoflurane in a glass chamber for induction and anesthetic plan was maintained by face mask with $1-2 \%$ isoflurane and subsequently buprenorphine $(0.1 \mathrm{mg} / \mathrm{kg})$ was administered subcutaneously as analgesia. All experiments were carried out in accordance with the standards and care approved by the institutional ethical animal care committee (reference 2015/VSC/PEA/00083). Tumor growth was checked visually weekly and mice were sacrificed by overdose of isoflurane at 8 weeks after taking blood from anaesthetised mice (as described previously) via the cardiac puncture method. After fixing in formaldehyde $4 \%$ and embedding in paraffin, xenograft tumors and mice organ samples were stained with Hematoxylin-eosin (HE) and with anti-VN as indicated previously. The Discovery anti-rabbit HQ reagent (Ventana Medical Systems Inc., Tucson, EE.UU.) was only used to detect VN expression in human NB cells.

\section{Results}

\section{VN is present in NB samples}

Positive VN immunoreactivity was observed in 85 out of 91 samples (93.4\%). A good consistency between subjective and digital image analysis was observed ( $p$-value $=0.000)$. The subjective assessment of $\mathrm{VN}$ pattern was weak to moderate (61 samples) and strong, (24 samples) (Fig. 1). Using digital image analysis, we found that: 1) Strong VN intensity was associated with a pericellular and intracellular location; it is mostly present in the pericellular region and stored intracellularly to a lesser 


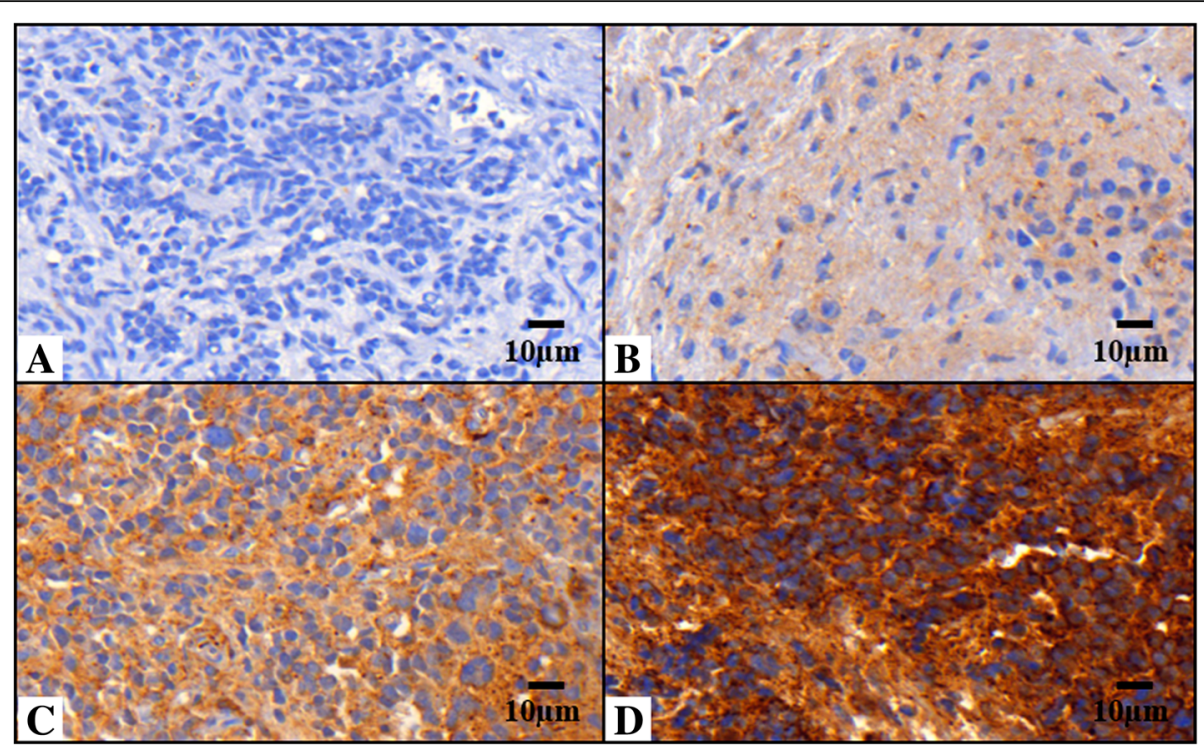

Fig. 1 Vitronectin pattern in neuroblastic tumors. Images immunostained with antibody anti-vitronectin (VN) at 40X. a Sample corresponding to negative VN. b and c Samples corresponding to weak to moderate VN expression and ECM distribution only (defined as interterritorial VN). $\mathbf{d}$ Sample with strong VN expression with pericellular and intracellular location (defined as territorial VN)

extent. The pericellular region concerned two tiny sites: the matrix adjacent to the cell membrane like a capsular territory, and a layer surrounding the capsular matrix of each cell or nests of grouped cells; we labeled this expression pattern territorial VN. 2) Weak to moderate VN intensity was associated with intercellular location (peripherally to territorial matrix); we named this expression interterritorial VN (Fig. 1).

The objective quantification patterns were considered as the \% $\mathrm{SA}$ of interterritorial $\mathrm{VN}$, territorial $\mathrm{VN}$ and $\mathrm{H}$-score. We noted that the \%SA of interterritorial VN and $\mathrm{H}$-score was low in control tissues, high in liver tissues and intermediate in NB samples. Nevertheless, the highest \%SA of territorial VN was found in NB samples. All VN and nuclei morphometric measurements are shown in Table 1. Median values of $\mathrm{VN}$ and nuclei quantity in relation to the INRG clinicopathological criteria are shown in Additional file 1: Table S1.

\section{High territorial VN expression pattern is associated with poor prognostic factors}

Mann-Whitney and Kruskal-Wallis tests demonstrated that strong $\mathrm{VN}$ intensity, territorial $\mathrm{VN}$ and high $\mathrm{H}$-score were statistically associated with unfavorable prognostic factors. These VN features were present in tumors from patients with metastatic stage (excluding high $\mathrm{H}$-score), uNB/pdNB histopathology, MNA, SCA profile, 11qD (excluding high $\mathrm{H}$-score), high-risk pretreatment stratification group and high genetic instability. No significant statistical relationship was observed between VN quantity and ploidy or histopathology category. The quantity of cell nuclei was higher in samples from patients aged $\geq 18$ months, metastatic stage, $\mathrm{uNB} / \mathrm{pdNB}$ histopathology, MNA, high-risk pretreatment stratification and high genetic instability. $p$-values for the relationship between VN patterns and INRG pre-treatment risk classification are shown in Table 2.

\section{The highest territorial VN expression pattern is related to poor survival}

Samples with the highest VN levels and corresponding to strong staining intensity, territorial location and $\mathrm{H}$-score $\geq \mathrm{Q}_{3}$ were associated with poorer 5-year EFS and lower 5-year OS, compared to patients whose samples presented a low VN level $\left(<\mathrm{Q}_{3}\right),(p$-value $<0.05)$. Furthermore, samples with nuclei density $\geq \mathrm{Q}_{3}$ were related to poorer 5-year EFS and lower 5-year OS (Fig. 2). To perform the multivariate survival analysis using Cox proportional hazards regression, we considered all INRG variables together with the $\mathrm{VN}$ morphometric variables considered as statistically significant by the log-rank test (Kaplan-Meier curves). This test showed that age $\geq 18$ months, uNB/pdNB histopathology and 11qD remained significant predictors for EFS. OS was influenced by age $\geq 18$ months, 11qD ( $p$-value $<0.05), M N A$ and territorial VN expression $(p$-value $<0.1)$ (Table 3$)$.

In vitro and in vivo studies demonstrate VN expression by malignant neuroblasts

Regarding VN expression in malignant neuroblasts, we observed low amounts of cytoplasmic VN dot drops expression in around 50\% of cells in both growth conditions 
Table 1 Description of the vitronectin and nuclei morphometric measurements of control tissues and NB primary tumors

\begin{tabular}{|c|c|c|c|c|c|c|c|}
\hline \multirow{2}{*}{\multicolumn{3}{|c|}{$\begin{array}{l}\text { Parameter } \\
\text { Normal control tissues other than liver }(n=12)\end{array}$}} & \multirow[t]{2}{*}{ Median } & \multirow[t]{2}{*}{ Mean } & \multirow[t]{2}{*}{ SD } & \multirow[t]{2}{*}{ Range } & \multirow[t]{2}{*}{$\mathrm{Q}_{3}$} \\
\hline & & & & & & & \\
\hline \multirow[t]{4}{*}{ IPP } & Nuclei & Density & 308.10 & 305 & 99.75 & $94.10-477.70$ & 355 \\
\hline & & $\% S A$ & 7.30 & 7.90 & 3.35 & $4-14$ & 8.80 \\
\hline & Inter. VN & $\% \mathrm{SA}$ & 1.57 & 3.92 & 5.70 & $0.42-17$ & 3.67 \\
\hline & Terr. VN & $\% \mathrm{SA}$ & 0.04 & 0.07 & 0.07 & $0-0.20$ & 0.15 \\
\hline \multirow[t]{4}{*}{ Densito } & VN ratio of pixels & Weak & 0.04 & 1 & 1.50 & $0-4$ & 1.75 \\
\hline & & Moderate & 2.25 & 10.95 & 13 & $0.06-35$ & 22.90 \\
\hline & & Strong & 1 & 2 & 2.60 & $0-9$ & 2.95 \\
\hline & H-score & & 20.45 & 46.40 & 52.51 & $0.16-163$ & 82.50 \\
\hline \multicolumn{8}{|c|}{ Liver samples $(n=5)$} \\
\hline \multirow[t]{4}{*}{ IPP } & Nuclei & Density & 616 & 1846.70 & 2384.30 & $472-6051.70$ & 3767.80 \\
\hline & & $\% \mathrm{SA}$ & 4 & 3.80 & 2.05 & $2-7$ & 5.50 \\
\hline & Inter. VN & $\% \mathrm{SA}$ & 20 & 19 & 11.40 & $3-31$ & 29.50 \\
\hline & Terr. VN & $\% \mathrm{SA}$ & 3 & 2.50 & 1.30 & $0.65-4$ & 3.50 \\
\hline \multirow[t]{4}{*}{ Densito } & VN ratio of pixels & Weak & 2.50 & 2.85 & 2.30 & $0.30-6$ & 5.15 \\
\hline & & Moderate & 67 & 64.55 & 8.30 & $50-71$ & 69.50 \\
\hline & & Strong & 12.75 & 13.50 & 2.70 & $10-17$ & 16 \\
\hline & H-score & & 175.80 & 172.60 & 11.60 & $152.25-181.35$ & 179.55 \\
\hline \multicolumn{8}{|c|}{ Primary tumors $(n=91)$} \\
\hline \multirow[t]{4}{*}{ IPP } & Nuclei & Density & 560 & 1074.25 & 1455.80 & $95-6793$ & 739 \\
\hline & & $\% \mathrm{SA}$ & 11.75 & 11.70 & 6.30 & $0.35-29.70$ & 15.50 \\
\hline & Inter. VN & $\% \mathrm{SA}$ & 9.35 & 12.25 & 10.95 & $0.02-40.97$ & 18.20 \\
\hline & Terr. VN & $\% \mathrm{SA}$ & 0.71 & 2.95 & 4.45 & $0.01-20.70$ & 4.50 \\
\hline \multirow[t]{4}{*}{ Densito } & VN ratio of pixels & Weak & 0.80 & 1.60 & 2.40 & $0.01-14.65$ & 2.10 \\
\hline & & Moderate & 35 & 36.10 & 24.70 & $0.05-88.10$ & 56.75 \\
\hline & & Strong & 3.55 & 12.85 & 17.85 & $0.01-61.85$ & 20.40 \\
\hline & H-score & & 110.91 & 112.85 & 78.55 & $1.07-257.60$ & 183.80 \\
\hline
\end{tabular}

Descriptors of vitronectin (VN) immunoreactivity and nuclei according to their morphometric measurements are shown. IPP: Image Pro-Plus; Densito: DensitoQuant; Inter.VN: Interterritorial VN; Terr.VN: Territorial VN. Density: number of objects/mm²; \%SA: percentage of stained area. SD: Standard deviation; $\mathrm{Q}_{3}$ : third quartile

Table 2 -values and relationship between vitronectin and nuclei morphometric measurements and poor prognostic factors

\begin{tabular}{|c|c|c|c|c|c|c|c|c|c|c|}
\hline \multicolumn{3}{|c|}{ Parameter } & \multirow{2}{*}{$\begin{array}{l}\text { Age: } \geq 18 \\
\text { months } \\
-\end{array}$} & \multirow{2}{*}{$\begin{array}{l}\text { Stage: M } \\
0.005 \uparrow\end{array}$} & \multirow{2}{*}{$\begin{array}{l}\text { Hist.D: uNB/ } \\
\text { pdNB } \\
0.007 \uparrow\end{array}$} & \multirow{2}{*}{$\begin{array}{l}\text { MYCN: } \\
\text { MNA } \\
0.001 \uparrow\end{array}$} & \multirow{2}{*}{$\begin{array}{l}\text { Gen. profile: } \\
\text { SCA } \\
-\end{array}$} & \multirow{2}{*}{$\begin{array}{l}\text { 11q: 11qD } \\
-\end{array}$} & \multirow{2}{*}{$\begin{array}{l}\text { Risk group: } \\
\text { high-risk } \\
0.001 \uparrow\end{array}$} & \multirow{2}{*}{$\begin{array}{l}\begin{array}{l}\text { Gen. } \\
\text { Instab.:High }\end{array} \\
0.003 \uparrow\end{array}$} \\
\hline IPP & Nuclei & Dens. & & & & & & & & \\
\hline & & $\% S A$ & $0.004 \uparrow$ & - & - & - & $0.018 \downarrow$ & - & - & - \\
\hline & Inter.VN & $\% \mathrm{SA}$ & - & - & - & - & - & - & - & - \\
\hline & Terr.VN & $\% \mathrm{SA}$ & - & $0.010 \uparrow$ & $0.001 \uparrow^{*}$ & $0.024 \uparrow$ & $0.001 \uparrow$ & $0.035 \uparrow$ & $0.008 \uparrow$ & $0.000 \uparrow$ \\
\hline \multirow[t]{4}{*}{ Densito } & VN ratio of pixels & Weak & - & - & - & - & - & - & - & - \\
\hline & & Mod. & - & - & - & - & - & - & - & - \\
\hline & & Strong & - & $0.037 \uparrow$ & $0.010 \uparrow^{*}$ & $0.011 \uparrow$ & $0.002 \uparrow$ & $0.021 \uparrow$ & $0.004 \uparrow$ & $0.010 \uparrow$ \\
\hline & $\mathrm{H}$-score & & - & - & $0.019 \uparrow$ & $0.040 \uparrow$ & $0.011 \uparrow$ & - & $0.008 \uparrow$ & $0.001 \uparrow$ \\
\hline
\end{tabular}

Only morphometric variables for vitronectin (VN) expression and nuclei having a statistically significant relationship with pre-treatment risk stratification factors are shown ( $p$-value< 0.05). IPP: Image Pro-Plus; Densito: DensitoQuant; Dens. Density (number of objects/mm2); \%SA: percentage of stained area; Inter. VN: Interterritorial VN; Terr.VN: Territorial VN; Mod.: moderate. M: metastatic; Hist.D: histopathologic differentiation; uNB: undifferentiated neuroblastoma; pdNB: poorly differentiated neuroblastoma; NOS was excluded from statistical analysis; Gen. Profile: genetic profile; SCA: segmental chromosomal aberration; MNA: MYCN amplified; 11qD: 11q deletion; Gen. Instab.: genetic instability. -: not statistically significant, $\uparrow / \downarrow$ : higher or lower median value for the poor-prognostic group(s). ${ }^{*}$ There are statistically significant differences between pdNB and uNB, within Strong VN $(p$-value $<0.05)$ and \%SA Territorial VN $(p$-value $<0.1)$ morphometric variables 


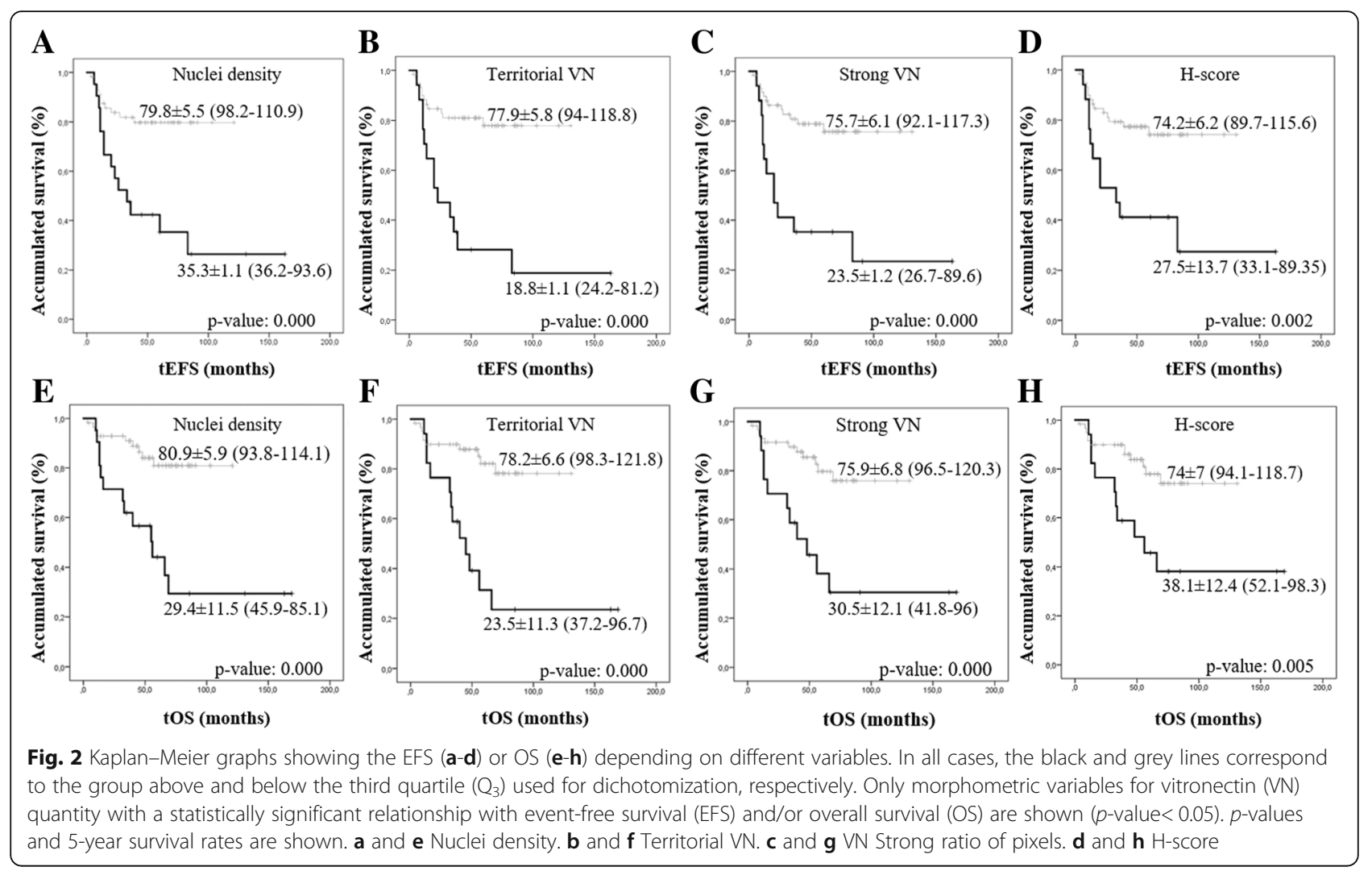

(complete and serum-free media) of both cell lines (Fig. 3). Tumor development after SH-SY5Y and SK-N-BE (2) inoculation was observed in $\mathrm{RAG}^{-/-} \mathrm{VN}^{+/+}$mice $(\mathrm{SH}-\mathrm{SY} 5 \mathrm{Y}=7 / 10$ and SK-N-BE $(2)=10 / 10)$ and $\mathrm{RAG1}^{-/-}$ $\mathrm{VN}^{-/-}$mice $(\mathrm{SH}-\mathrm{SY} 5 \mathrm{Y}=9 / 10$ and SK-N-BE $(2)=9 / 10)$.

Table 3 Cox Regression of morphometric vitronectin variables and INRG prognostic factors

\begin{tabular}{|c|c|c|c|c|c|}
\hline ariable & $B$ & E & Wald & $\operatorname{Exp}(B)(95 \%$ Cl) & $p-v$ \\
\hline \multicolumn{6}{|l|}{ EFS } \\
\hline Age & 1.361 & .526 & 6.696 & $.39-10.92)$ & 0.010 \\
\hline Hist.D (uNB/pdNB) & 1.073 & 0.411 & 6.806 & $2.924(1.30-6.54)$ & 0.009 \\
\hline $11 q \mathrm{~s}$ & 0.883 & 424 & 4.332 & & \\
\hline \multicolumn{6}{|l|}{ OS } \\
\hline Age ( & 1.320 & 603 & 4.797 & 3.745 & 0.029 \\
\hline 11q status (11qD) & 1.309 & 0.469 & 7.785 & 3.702 & 0.00 \\
\hline${ }^{*} M Y C N(M N A)$ & 0.857 & 0.472 & 3.296 & 2.357 & 0.06 \\
\hline${ }^{*}$ Terr. VN_Q ${ }_{3}$ & 0.852 & 0.480 & 3.154 & $2.344(0.92-6)$ & 0.076 \\
\hline \multicolumn{6}{|c|}{$\begin{array}{l}\text { Significant INRG prognostic parameters and morphometric vitronectin (VN) } \\
\text { measurements predictive of poor outcome in neuroblastoma (NB) patients } \\
\text { based on event-free survival (EFS) and overall survival (OS) with } p \text {-value }<0.05 \\
\text { and * } p \text {-value }<0.1 \text {. Hist.D: histopathologic differentiation; uNB: undifferentiated } \\
\text { neuroblastoma; pdNB: poorly differentiated neuroblastoma; 11qD: } 11 \mathrm{q} \\
\text { deletion; MNA: MYCN amplified; Terr.VN_Q } Q_{3} \text { : Territorial vitronectin } \\
\text { dichotomized at the third quartile. B: Beta coefficient; S.E: Standard Error; Cl: } \\
\text { Confidence interval. Coefficients Exp (B) }>1 \text { indicate that high values of this } \\
\text { parameter increase the probability of it being an independent poor } \\
\text { prognostic factor }\end{array}$} \\
\hline
\end{tabular}

We found no significant differences between tumor growth in control compared to experimental $\mathrm{RAG1}^{-1-}$ $\mathrm{VN}^{-1-}$ in any of the cell lines. Tumors displayed small and limited intra-adrenal, and large abdominal solid masses with a heterogeneous macroscopic appearance, as well as moderate infiltrative growth into surrounding tissues such as perirenal fat, pancreas and liver, both in animal models and in NB cell lines. Regarding histopathology, solid tumors from the SH-SY5Y cell line presented 30-90\% undifferentiated neuroblastic cells, non-evident nucleolus, high mitosis-karyorrhexis index (IMK) and between 5 and 50\% necrosis. With respect to the samples derived from cell line SK-N-BE (2), these were characterized by being $\mathrm{uNB}$ with a mean of $40-70 \%$ neuroblasts with evident nucleolus, high IMK, and 5-50\% necrosis. Highly dense cytoplasmic VN staining was similar in control and experimental mice derived from both cell lines (Fig. 3).

\section{Discussion}

$\mathrm{VN}$ is an attachment glycoprotein that directs cell migration, progression, adhesion and differentiation in many biological and pathological processes [13, 15, 30, 31]. By introducing advanced morphometric methodology, we have been able to demonstrate and robustly quantify $\mathrm{VN}$ as an important ECM component in aggressive NB synthetized by undifferentiated neuroblasts. We have found two $\mathrm{VN}$ expression patterns which reflect the 


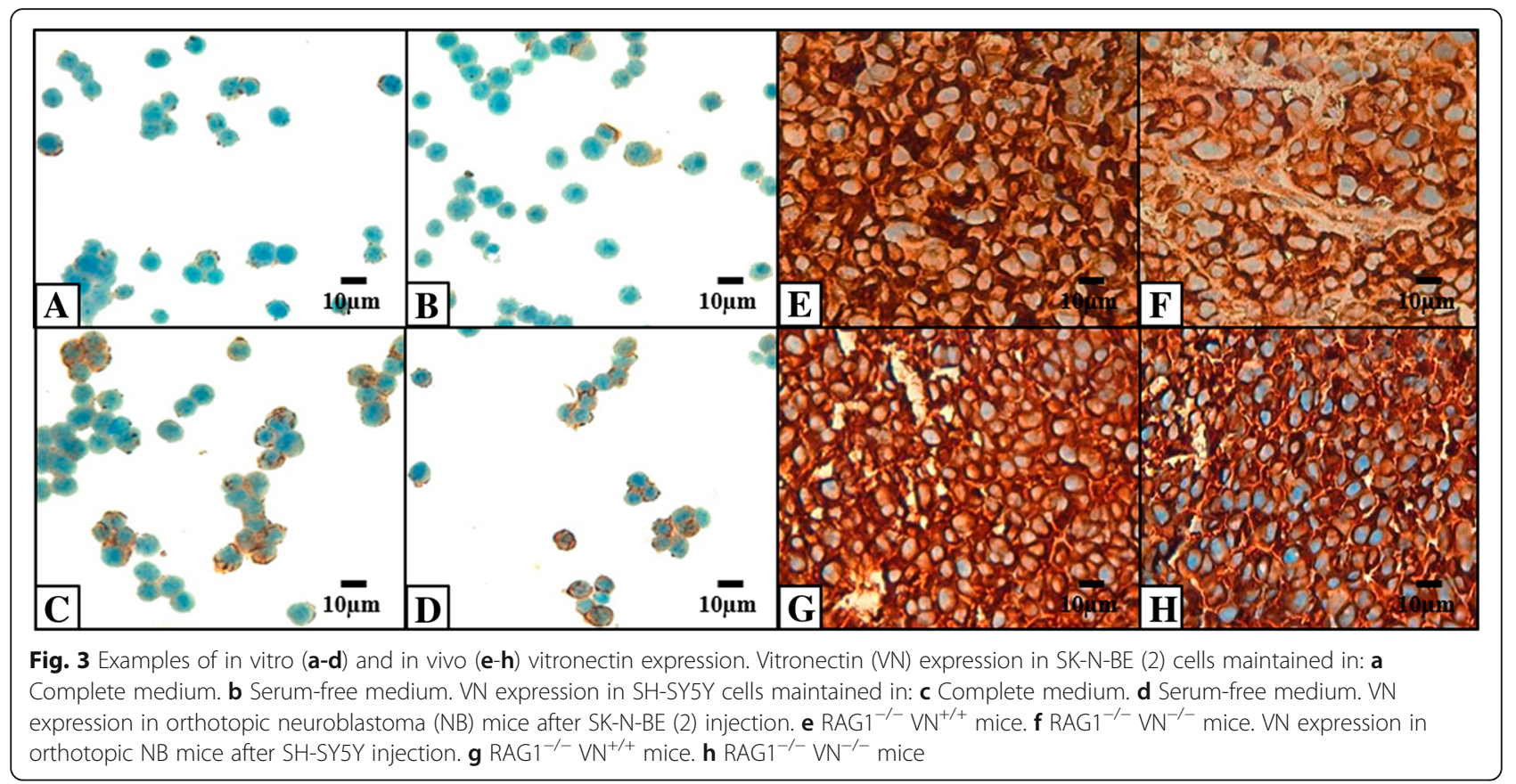

secretion time and role of this glycoprotein that has typically been described for ECM constituents in cartilage: the territorial $\mathrm{VN}$ pattern, where $\mathrm{VN}$ is synthetized and recently incorporated to the newly formed matrix facilitating mechanical stresses of tumor cells, and the interterritorial $\mathrm{VN}$ pattern, where $\mathrm{VN}$ has been integrated some time ago to the matrix contributing to metabolic and biomechanical properties of several tumor tissue elements.

Some contradictory studies of VN expression in NB have been described [12, 27, 32]. Gladson et al. 1997, showed $\mathrm{VN}$ expression in differentiating neuroblastic tumors and noted its attachment role in retinoic-acid differentiated neuroblastic cells stimulating in vivo differentiation [12]. Later NB studies detected an overexpression of $\alpha_{\mathrm{v}} \beta_{3}$ integrin and uPAR, both of which are important VN ligands, in high-risk NB [27, 32]. From a larger cohort of neuroblastic tumors, our immunohistochemical results revealed $\mathrm{VN}$ expression in $\mathrm{NB}$ and GNB, with a high territorial VN expression in undifferentiated neuroblasts. Our findings are in agreement with the most recent studies mentioned above and the differences from the earlier study [12] could be explained by cohort size. Using digital pathology techniques, we were able to accurately provide a connection between intensity and location. These techniques assure the standardization of all measurements and minimize inter-observer differences [33, 34] and can easily be reproduced in future studies. We are currently carrying out topological analysis on the histopathological images to evaluate non-cellular VN distribution features related to the tumor microenvironment. Our topological approach will capture different aspects of the VN distribution to improve the classification of biopsy samples from NB samples.

The in vitro and vivo preliminary results in the present study mainly focused on human $\mathrm{NB}$, were to emphasize the VN secretion by both NB cell lines and highlight the tumor and/or host microenvironment influence in their $\mathrm{VN}$ synthesis. We found that in vitro NB cells expressed a low quantity of $\mathrm{VN}$ as a small cytoplasmic dot drops pattern and that the in vivo experiments revealed a high amount of $\mathrm{VN}$ as a dense cytoplasmic pattern with no differences in VN staining pattern or tumor growth rate between $\mathrm{RAG}^{-/-} \mathrm{VN}^{+/+}$and $\mathrm{RAG1}^{-/-} \mathrm{VN}^{-/-}$mice. The increased VN secretion by tumor cells, which produces mechanical stress, generates an initial stiff matrix and results in disrupted cell-cell and cell-ECM interactions, promoting tumor proliferation in both mice strains, as described in ovarian cancer, through the breakdown of $\mathrm{VN}$ bonds to improve metastasis [35]. We confirmed that: a) Fetal bovine serum (FBS) does not contribute to a higher amount of $\mathrm{VN}$ in tumor cells as reported by Gladson et al. [36] and b) the importance of VN in NB tumor growth due to its high presence in vivo. These findings reinforce the previously described $\mathrm{VN}$ role in improving the migratory ability of tumor cells in NB and suggest that in vivo tumor cells produce $\mathrm{VN}$ to achieve greater migratory capacity. Furthermore, given the importance of $\mathrm{VN}$ in breast cancer [37], we are developing experiments to clarify the role of VN in vivo in NB tumor growth. Serial tumor passages will allow VN secretion by neuroblasts to be modified in relation to a host microenvironment, affecting tumor growth and genetic instability, as occurs in hormone-dependent tumors [38]. Therefore, although 
xenotranplanted neuroblastic cells continue to synthetize $\mathrm{VN}$, the absence of liver $\mathrm{VN}$ in the host would have a subtle role in the secretory ability of malignant neuroblasts, but some long-term influence on cell proliferation and tumor aggressiveness.

We stress that a high territorial VN expression pattern could contribute to tumor cell adhesion, thus promoting invasion and metastasis in $\mathrm{NB}$, suggesting that $\mathrm{VN}$ or its ligands could be used as targets when developing therapeutic strategies for modulating the relationship between tumor cells and the ECM. In fact, the highest presence of territorial VN protein in the present cohort is related to unfavorable independent prognostic INRG variables. The high presence of territorial $\mathrm{VN}$ staining in tumors from patients with metastasic stage and unfavorable histology, would lead to higher migration ability of tumor cells by anchorage to fibers and proteoglycans, as well as disrupted cell adhesion and spreading via interactions with specific $\alpha_{v} \beta_{3}$ and $\alpha_{v} \beta_{5}$ integrins, uPAR and PAI-1 in a stiff matrix. In the case of tumors with genetic instability, a huge presence of territorial $\mathrm{VN}$ would generate mechanical alterations in ECM, which would be transmitted to the nuclear matrix and would modulate the response of intracellular signals activating genetic and epigenetic mechanisms of instability in these tumors [39].

The main therapeutic goal would be to focus on decreasing $\mathrm{VN}$ expression or to inhibit its joining with $\alpha_{v} \beta_{3}$ integrin, uPAR or PAI- 1 , thus depriving the tumor cells of the mechanical forces necessary to create the appropriate environment for invasion [40-42]. Via its ligands, VN has a role in biochemical cell-ECM pathways which could be used as therapeutic targets; however, no drug against cell-ECM interactions has yet been approved, although some trials are ongoing as described below.

$\alpha_{v} \beta_{3}$ and $\alpha_{v} \beta_{5}$ integrins bind to the arginine-glycine-aspartate (RGD) VN sequence and are key factors in angiogenesis. It has been observed that $\mathrm{VN}$ activates vascular endothelial growth factor receptor 2 (VEGFR-2) via $\alpha_{v} \beta_{3}$, thus contributing to angiogenesis [43]. As anti- $\alpha_{\mathrm{v}} \beta_{3}$ integrin targeted drugs: Vitaxin, Intetumubab (CNTO 95) and 17E6 (EMD 525797) are in different phases of clinical trials [44], also in vitro melanoma research has displayed metastasis retardation using IH1062, an $\alpha_{v} \beta_{3}$ integrin inhibitor that blocks the binding of this integrin to $\mathrm{VN}$ [45].

UPAR is a protease that binds to VN in the RGD motif or N-terminal somatomedin B (SMB) domain. It has been observed that this union initiates integrin pathways that promoting migration $[46,47]$. In addition, when UPAR binds to urokinase plasminogen activator (uPA), it causes the cleaving of plasminogen to produce plasmin that mediates the degradation of the ECM [48]. An in vivo study into a monoclonal anti-uPAR antibody
(ATN-658) reported that this antibody inhibits tumor cell proliferation in prostate cancer [49].

Finally, PAI-1 is a protease inhibitor of the serpins family that binds to the SMB domain of $\mathrm{VN}$ where its main function is uPA inhibition. Thus, PAI-1 participates in the uPA/uPAR proteolytic cascade, as well as interfering in the binding of uPAR and $\alpha_{\mathrm{v}}$ integrins family in the SMB domain and RGD motif to VN, respectively [50]. In fact, an in vivo study of NB using PAI-1 deficient mice showed a reduction in tumor size [51]. In vitro and in vivo studies on the inhibition of PAI-1 using compounds such as TM5441, TM5275 and SK-216 have demonstrated toxic effects in cancer cells $[52,53]$.

\section{Conclusions}

In conclusion, NB samples of patients with poor prognostic factors are characterized by the highest territorial $\mathrm{VN}$ expression pattern. Our findings suggest the importance of extensive studies on $\mathrm{VN}$ as a possible target for inhibiting interactions in NB.

\section{Additional files}

\begin{abstract}
Additional file 1: Table S1. Descriptors and median values of vitronectin and nuclei morphometric variables in the present cohort. (DOCX $19 \mathrm{~kb}$ )
\end{abstract}

Additional file 2: Table S2. Description of the image analysis process. (DOCX $15 \mathrm{~kb}$ )

Additional file $\mathbf{3}$ Figure S1. Examples of how these applications work in vitronectin samples. A. Liver sample image immunostained for vitronectin (VN) without segmentation. B. Image of liver control sample segmentation with the DensitoQuant module (Pannoramic viewer software). C. Image of liver control sample segmentation with Image ProPlus software. D. Primary neuroblastoma (NB) sample immunostained for VN without segmentation. E. Image of NB sample segmentation with the DensitoQuant module (Pannoramic viewer software). F. Image of NB sample segmentation with Image Pro-Plus software. (ZIP 8306 kb)

Additional file 4: Table S3. Growth conditions of NB human cell lines. (DOCX $14 \mathrm{~kb})$

\section{Abbreviations}

\%SA: Percentage of stained area; 11qD: 11q deleted; 11qND: 11q nondeleted; DensitoQ: DensitoQuant; dNB: Differentiating neuroblastoma; ECM: Extracellular matrix; EFS: Event-free survival; GNB: Ganglioneuroblastoma; INRG: International Neuroblastoma Risk Group; IPP: Image Pro-Plus; MNA: MYCN amplified; MNNA: MYCN non-amplified; NB: Neuroblastoma; NCAs: Numerical chromosomal aberrations; OS: Overall survival; PAI-1: Plasminogen activator inhibitor-1; pdNB: Poorly differentiated neuroblastoma; $\mathrm{Q}_{3}$ : Third quartile; RGD: Arginine-glycine-aspartate motif; SCAs: Segmental chromosomal aberrations; SMB: Somatomedin B domain; TMAs: Tissue microarrays; UNB: Undifferentiated neuroblastoma; uPA: Urokinase plasminogen activator; UPAR: Urokinase plasminogen activator receptor; VN: Vitronectin

\section{Acknowledgments}

The authors would like to thank Elisa Alonso for technical support, Francisco Santonja for statistical assistance and Kathryn for English correction. We also thank the Spanish Society of Pediatric Hemato-Oncology (SEHOP) for patient data management.

\section{Funding}

This study was supported by the FAECC (contract 2015, FAECC2015/006), CIBERONC (CB16/12/00484) and FIS (PI17/01558, Institute of Health Carlos III, 
Madrid/ERDF). The funders had no involvement in the research process or the preparation and submission of the article.

\section{Availability of data and materials}

The datasets used and analyzed in the current study are available from the corresponding author on reasonable request.

\section{Authors' contributions}

RB-P carried out the in vitro and in vivo experiments, the image and statistical analyses of the samples, and wrote the original draft of the manuscript. IN: contributed to in vivo experiments and suggested draft changes. AC provided the pediatric clinical data used for this study. SN carried out the histopathological analyses of the samples and reviewed the paper and suggested draft changes. RN elaborated the concept and designed the study, reviewed the paper and suggested draft changes. All authors read and approved the final manuscript.

\section{Ethics approval and consent to participate}

This study was approved by the Ethical Committee of the University of Valencia (reference B.0000339 29/01/2015). Participants or their family members/legal guardians provided written informed consent for histological and genetic studies performed in our laboratory.

The animal experiments were carried out in accordance with the standards and care approved by the institutional ethical animal care committee (reference 2015/NSC/PEA/00083)

\section{Consent for publication}

Not applicable

\section{Competing interests}

The authors declare that they have no competing interests.

\section{Publisher's Note}

Springer Nature remains neutral with regard to jurisdictional claims in published maps and institutional affiliations.

\section{Author details}

${ }^{1}$ Pathology Department, Medical School, University of Valencia-INCLIVA, Valencia, Spain. ${ }^{2}$ CIBERONC, Madrid, Spain. ${ }^{3}$ Central Support Service for Experimental Research (SCSIE), University of Valencia, Valencia, Spain. ${ }^{4}$ Pediatric Oncology Unit, University and Polytechnic Hospital La Fe, Valencia, Spain.

Received: 19 June 2018 Accepted: 8 May 2019

Published online: 22 May 2019

\section{References}

1. Xiong $G, X u R$. Function of cancer cell-derived extracellular matrix in tumor progression. J Cancer Metastasis Treat. 2016;2:357-64.

2. Pickup MW, Mouw JK, Weaver VM. The extracellular matrix modulates the hallmarks of cancer. EMBO Rep. 2014;15(12):1243-53.

3. Wells RG. The role of matrix stiffness in regulating cell behavior. Hepatology. 2008:47(4):1394-400.

4. Wirtz D, Konstantopoulos K, Searson PC. The physics of cancer: the role of physical interactions and mechanical forces in metastasis. Nat Rev Cancer. 2011;11(7):512-22

5. lozzo RV, Sanderson RD. Proteoglycans in cancer biology, tumou microenvironment and angiogenesis. J Cell Mol Med. 2011;15(5):1013-31.

6. Oskarsson T. Extracellular matrix components in breast cancer progression and metastasis. Breast. 2013;22(Suppl 2):S66-72.

7. Vincent $\mathrm{T}$, Mechti N. Extracellular matrix in bone marrow can mediate drug resistance in myeloma. Leuk Lymphoma. 2005;46(6):803-11.

8. Lin HH, Lin HK, Lin H, Chiou YW, Chen HW, Liu CY, et al. Mechanical phenotype of cancer cells: cell softening and loss of stiffness sensing. Oncotarget. 2015;6(25):20946-58.

9. Preissner KT. Structure and biological role of vitronectin. Annu Rev Cell Biol. 1991;7:275-310.

10. Schvartz I, Seger D, Shaltiel S. Vitronectin. Int J Biochem Cell Biol. 1999;31(5): 539-44

11. Seiffert D. Constitutive and regulated expression of vitronectin. Histol Histopathol. 1997;12(3):787-97.
12. Gladson $\mathrm{CL}$, Dennis C, Rotolo TC, Kelly DR, Grammer JR. Vitronectin expression in differentiating neuroblastic tumors: integrin alpha $\vee$ beta 5 mediates vitronectin-dependent adhesion of retinoic-acid-differentiated neuroblastoma cells. Am J Pathol. 1997;150(5):1631-46.

13. Dimova T, Georgieva R, Petlov D, Lazarova S. Comparative study on the expression of fibronectin, vitronectin, $\alpha_{5} \beta_{1}, \beta_{3}$ and $a_{v}$ integrins in goat and pig adrenal glands. Comptes rendus de l'Academie bulgare des Sciences. 2005;12:1457-62.

14. Edwards S, Lalor PF, Tuncer C, Adams DH. Vitronectin in human hepatic tumours contributes to the recruitment of lymphocytes in an alpha $v$ beta3independent manner. Br J Cancer. 2006:95(11):1545-54.

15. Yasumitsu H, Seo N, Misugi E, Morita H, Miyazaki K, Umeda M. Vitronectin secretion by hepatic and non-hepatic human cancer cells. In Vitro Cell Dev Biol Anim. 1993;29A(5):403-7.

16. Preissner KT. The role of vitronectin as multifunctional regulator in the hemostatic and immune systems. Blut. 1989;59(5):419-31.

17. Madsen CD, Ferraris GM, Andolfo A, Cunningham O, Sidenius N. UPARinduced cell adhesion and migration: vitronectin provides the key. J Cell Biol. 2007:177(5):927-39.

18. Gladson CL, Cheresh DA. Glioblastoma expression of vitronectin and the alpha $v$ beta 3 integrin. Adhesion mechanism for transformed glial cells. J Clin Invest. 1991;88(6):1924-32

19. Schneider G, Bryndza E, Poniewierska-Baran A, Serwin K, Suszynska M, Sellers $Z P$, et al. Evidence that vitronectin is a potent migration-enhancing factor for cancer cells chaperoned by fibrinogen: a novel view of the metastasis of cancer cells to low-fibrinogen lymphatics and body cavities. Oncotarget. 2016:7(43):69829-43.

20. Shi K, Lan RL, Tao X, Wu CY, Hong HF, Lin JH. Vitronectin significantly influences prognosis in osteosarcoma. Int J Clin Exp Pathol. 2015;8(9):11364-71.

21. Cheung NK, Dyer MA. Neuroblastoma: developmental biology, cancer genomics and immunotherapy. Nat Rev Cancer. 2013;13(6):397-411.

22. Cohn SL, Pearson AD, London WB, Monclair T, Ambros PF, Brodeur GM, et al. The international neuroblastoma risk group (INRG) classification system: an INRG task force report. J Clin Oncol. 2009;27(2):289-97.

23. Tadeo I, Berbegall A, Castel V, García-Miguel P, Callaghan R, Påhlman S, et al. Extracellular matrix composition defines an ultra-high-risk group of neuroblastoma within the high-risk patient cohort. Br J Cancer. 2016;115(4): 480-9.

24. Tadeo I, Berbegall A, Navarro S, Castel V, Noguera R. A stiff extracellular matrix is associated with malignancy in peripheral neuroblastic tumors. Pediatr Blood Cancer. 2017;64(9). https://doi.org/10.1002/pbc.26449.

25. Tadeo I, Bueno G, Berbegall A, Fernández-Carrobles M, Castel V, García-Rojo $M$, et al. Vascular patterns provide therapeutic targets in aggressive neuroblastic tumors. Oncotarget. 2016;7(15):19935-47.

26. Tadeo I, Gamero-Sandemetrio E, Berbegall AP, Navarro S, Cañete A, Noguera R. 1 p36 deletion results in a decrease in glycosaminoglycans which is associated with aggressiveness in neuroblastic tumors. Histol Histopathol. 2018;33:487-95

27. Erdreich-Epstein A, Shimada H, Groshen S, Liu M, Metelitsa LS, Kim KS, et al. Integrins alpha(v)beta3 and alpha(v)beta5 are expressed by endothelium of high-risk neuroblastoma and their inhibition is associated with increased endogenous ceramide. Cancer Res. 2000;60(3):712-21.

28. Ambros IM, Brunner C, Abbasi R, Frech C, Ambros PF. Ultra-high density SNParray in neuroblastoma molecular diagnostics. Front Oncol. 2014;4:202.

29. Lavorato-Rocha AM, Akagi EM, de Melo Maia B, Rodrigues IS, Botelho MC Marchi FA, et al. An integrative approach uncovers biomarkers that associate with clinically relevant disease outcomes in vulvar carcinoma. Mol Cancer Res. 2016;14(8):720-9.

30. Niu Y, Zhang L, Bi X, Yuan S, Chen P. Evaluation of Vitronectin expression in prostate Cancer and the clinical significance of the Association of Vitronectin Expression with prostate specific antigen in detecting prostate Cancer. Urol J. 2016:13(1):2527-32.

31. Ortega-Martinez I, Gardeazabal J, Erramuzpe A, Sanchez-Diez A, Cortes J, Garcia-Vazquez MD, et al. Vitronectin and dermcidin serum levels predict the metastatic progression of AJCC I-II early-stage melanoma. Int J Cancer. 2016;139(7):1598-607.

32. Li P, Gao Y, Ji Z, Zhang X, Xu Q, Li G, et al. Role of urokinase plasminogen activator and its receptor in metastasis and invasion of neuroblastoma. Pediatr Surg. 2004;39(10):1512-9.

33. Nast CC, Lemley KV, Hodgin JB, Bagnasco S, Avila-Casado C, Hewitt SM, et al. Morphology in the digital age: integrating high-resolution description of 
structural alterations with phenotypes and genotypes. Semin Nephrol. 2015; 35(3):266-78.

34. Mulrane L, Rexhepaj E, Penney S, Callanan JJ, Gallagher WM. Automated image analysis in histopathology: a valuable tool in medical diagnostics. Expert Rev Mol Diagn. 2008;8(6):707-25.

35. Kenny HA, Kaur S, Coussens LM, Lengyel E. The initial steps of ovarian cancer cell metastasis are mediated by MMP-2 cleavage of vitronectin and fibronectin. J Clin Invest. 2008;118(4):1367-79.

36. Gladson CL, Wilcox JN, Sanders L, Gillespie GY, Cheresh DA. Cerebral microenvironment influences expression of the vitronectin gene in astrocytic tumors. J Cell Sci. 1995;108 ( Pt 3:947-56.

37. Pirazzoli V, Ferraris GM, Sidenius N. Direct evidence of the importance of vitronectin and its interaction with the urokinase receptor in tumor growth. Blood. 2013;121(12):2316-23.

38. Chang C, Lee SO, Yeh S, Chang TM. Androgen receptor (AR) differential roles in hormone-related tumors including prostate, bladder, kidney, lung, breast and liver. Oncogene. 2014;33(25):3225-34.

39. nGraham DM, Burridge K. Mechanotransduction and nuclear function. Curr Opin Cell Biol. 2016;40:98-105.

40. Sloan EK, Pouliot N, Stanley KL, Chia J, Moseley JM, Hards DK, et al. Tumorspecific expression of alphavbeta3 integrin promotes spontaneous metastasis of breast cancer to bone. Breast Cancer Res. 2006:8(2):R20.

41. Mauro CD, Pesapane A, Formisano L, Rosa R, D'Amato V, Ciciola P, et al. Urokinase-type plasminogen activator receptor (UPAR) expression enhances invasion and metastasis in RAS mutated tumors. Sci Rep. 2017;7(1):9388.

42. Harbeck N, Kruger A, Sinz S, Kates RE, Thomssen C, Schmitt M, et al. Clinical relevance of the plasminogen activator inhibitor type 1-a multifaceted proteolytic factor. Onkologie. 2001;24(3):238-44.

43. Li R, Luo M, Ren M, Chen N, Xia J, Deng X, et al. Vitronectin regulation of vascular endothelial growth factor-mediated angiogenesis. J Vasc Res. 2014; 51(2):110-7.

44. Holle AW, Young JL, Spatz JP. In vitro cancer cell-ECM interactions inform in vivo cancer treatment. Adv Drug Deliv Rev. 2016;97:270-9.

45. Zhang $Y$, Yang $M$, Ji Q, Fan D, Peng $H$, Yang $C$, et al. Anoikis induction and metastasis suppression by a new integrin alphavbeta3 inhibitor in human melanoma cell line M21. Investig New Drugs [Internet. 2011;29(4):666-73.

46. Montuori N, Pesapane A, Rossi FW, Giudice V, De Paulis A, Selleri C, et al. Urokinase type plasminogen activator receptor (UPAR) as a new therapeutic target in cancer. Transl Med UniSa. 2016:15:15-21.

47. Noh H, Hong S, Huang S. Role of urokinase receptor in tumor progression and development. Theranostics. 2013;3(7):487-95.

48. Smith HW, Marshall CJ. Regulation of cell signalling by uPAR. Nat Rev Mol Cell Biol. 2010;11(1):23-36.

49. Rabbani SA, Ateeq B, Arakelian A, Valentino ML, Shaw DE, Dauffenbach LM, et al. An anti-Urokinase plasminogen activator receptor antibody (ATN-658) blocks prostate Cancer invasion, migration, growth, and experimental skeletal metastasis in vitro and in vivo. Neoplasia. 2010;10:778-88.

50. Andreasen PA, Egelund R, Petersen HH. The plasminogen activation system in tumor growth, invasion, and metastasis. Cell Mol Life Sci. 2000;57(1):25-40.

51. Bajou K, Peng H, Laug WE, Maillard C, Noel A, Foidart JM, et al. Plasminogen activator inhibitor-1 protects endothelial cells from FasL-mediated apoptosis. Cancer Cell. 2008;14(4):324-34.

52. Masuda T, Hattori N, Senoo T, Akita S, Ishikawa N, Fujitaka K, et al. SK-216, an inhibitor of plasminogen activator inhibitor-1, limits tumor progression and angiogenesis. Mol Cancer Ther. 2013;12(11):2378-88.

53. Placencio VR, Ichimura A, Miyata T, DeClerck YA. Small molecule inhibitors of plasminogen activator Inhibitor-1 elicit anti-tumorigenic and antiAngiogenic activity. PLoS One. 2015;10(7):e0133786.

\section{Ready to submit your research? Choose BMC and benefit from:}

- fast, convenient online submission

- thorough peer review by experienced researchers in your field

- rapid publication on acceptance

- support for research data, including large and complex data types

- gold Open Access which fosters wider collaboration and increased citations

- maximum visibility for your research: over $100 \mathrm{M}$ website views per year

At BMC, research is always in progress.

Learn more biomedcentral.com/submissions 